\title{
Predictors of therapeutic failure among naïve patients with pulmonary tuberculosis: contribution of diabetes mellitus and metformin therapy
}

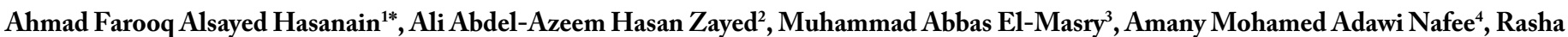 \\ Abdel-Monem Hassan Attia ${ }^{5}$ and Sherif Mohamed Abdel-Aal ${ }^{6}$ \\ ${ }^{1}$ Department of Tropical Medicine and Gastroenterology, Faculty of Medicine, Assiut University, Egypt \\ ${ }^{2}$ Department of Chest Disease, Faculty of Medicine, Assiut University, Egypt \\ ${ }^{3}$ Department of Internal Medicine, Faculty of Medicine, Assiut University, Egypt \\ ${ }^{4}$ Department of Microbiology and Immunology, Faculty of Medicine, Assiut University, Egypt \\ ${ }^{5}$ Department of Parasitology, Faculty of Medicine, Assiut University, Egypt \\ ${ }^{6}$ Department of Diagnostic Radiology, Faculty of Medicine, Assiut University, Egypt
}

\begin{abstract}
Background: The rising epidemic of diabetes mellitus (DM) can increase the global burden of tuberculosis (TB). Our research hypothesis is that comorbidities (noninfectious and infectious) can affect the therapeutic response to antituberculosis therapy (ATT). The aim of this study is to determine the frequency of therapeutic failure among the naive patients with pulmonary TB and to explore the predictors of therapeutic failure.
\end{abstract}

Patients and methods: The study included 483 consecutive, naïve, patients with pulmonary TB. The diagnosis of pulmonary TB relied on positive culture of sputum. For all the study population, clinical evaluation, imaging studies (including chest radiography), and laboratory investigations (including microscopic examination for urine and stool) were conducted. All the enrolled patients received the standard of care ATT therapy.

Results: The mean age of the study population was $37 \pm 12.5$ years; $53.8 \%$ of them were males. Therapeutic failure developed in $31.7 \%$ of the patients; $17 \%$ of the patients had adverse effects. Diabetes mellitus, helminth infection, tobacco smoking, and lack of metformin therapy were the predictors of therapeutic failure.

Conclusions: In conclusion, the therapeutic failure rate of ATT among the Egyptian, naïve patients with pulmonary TB is increasing. The predictors of therapeutic failure include DM, lack of metformin use, helminth infection, and tobacco smoking.

\section{Introduction}

Tuberculosis (TB), with an estimated incidence of 10.4 million new cases and 1.5 million deaths, is considered as a global, major, public health problem [1]. Cure rates, ranging between $90 \%$ and $95 \%$, are expected to be achieved using the standard of care antituberculosis therapy (ATT) (isoniazid (INH), rifampin (RIF), pyrazinamide (PZA), and ethambutol (EMB), for 2 months, followed by INH and RIF, for 4 months) [2]. Monthly sputum cultures are recommended for monitoring the therapeutic response of the patients with pulmonary (TB), until they achieve two consecutive negative culture results by the end of therapy [3]. Therapeutic failure of pulmonary TB is defined as positive sputum culture at the fourth month or later during treatment [4]. Culture is considered as the reference diagnostic tool of TB [5].

The growing epidemic of diabetes mellitus (DM) may lead to a rise in the number of patients from 415 million in 2015 to 642 million by 2040, world-wide [6]. Thus, co-existence of TB and DM is not uncommon. Patients with DM have a two to four-fold increased risk of developing active TB [7-9]. In addition, DM has impact on clinical presentation and course of TB; cavitary pulmonary TB and TB-related mortality are more frequent among TB patients with DM compared to TB without DM $[10,11]$. Regarding its effect on therapeutic outcome of
TB, DM leads to delayed conversion of sputum culture, increased risk of therapeutic failure failure, relapse, and mortality [12]. Subsequently, the rising epidemic of DM can increase the global burden of TB.

Metabolic similarity exists between DM and TB with common underlying hyperglycemia, which can be transiently induced by fever in TB, elevated serum levels of pro-inflammatory cytokines, and a state of oxidative stress $[13,14]$. Thus, the use of metformin-augmented ATT may enhance the therapeutic response among patients with TB, even among the nondiabetic patients $[15,16]$. Our research hypothesis is that comorbidities (noninfectious and infectious) can affect the therapeutic response to ATT. The aim of this study is to determine the frequency of therapeutic failure among the naive patients with pulmonary TB and to explore the predictors of therapeutic failure.

${ }^{\star}$ Correspondence to: Ahmad Farooq Alsayed Hasanain, Department of Tropical Medicine and Gastroenterology, Assiut University Hospitals, Assiut, Egypt, E-mail: af.hasanain@outlook.com

Key words: pulmonary tuberculosis, diabetes mellitus, metformin

Received: May 14, 2018; Accepted: May 31, 2018; Published: June 04, 2018 


\section{Patients and Methods}

\section{Study design}

A hospital-based, prospective, cohort study was conducted.

\section{Study location}

The study population was recruited from patients attending the outpatient clinics and admitted to the inpatient sectors of the Department of Chest Disease, the Department of Tropical Medicine and Gastroenterology, and the Department of Internal Medicine.

\section{Study duration:}

The study population was recruited during the period from March 2015 to December 2017.

\section{Inclusion criteria:}

The study included 500 consecutive, naïve, patients with pulmonary TB. The diagnosis of pulmonary TB relied on positive culture of sputum (on Löwenstein-Jensen medium) performed by an experienced microbiologist.

\section{Exclusion criteria:}

Patients less than 18 years old and pregnant patients were excluded from the study. In addition, patients with clinical, radiological, and/ or microbiological evidence of extrapulmonary $\mathrm{TB}$, and those who received any antimicrobial therapy after the onset of illness were not included.

\section{Methods}

For all the study population, clinical evaluation (medical history and physical examination with estimation of weight and height), imaging studies (including chest radiography and abdominal ultrasonography), and laboratory investigations were conducted. The use of acid suppressive, corticosteroid, immunosuppressant, and antineoplastic therapies was considered significant if it was for two weeks or more during the period of receiving treatment for acute/ subacute brucellosis. Overweight was defined as a BMI of $25 \mathrm{~kg} / \mathrm{m}^{2}$ to $<30 \mathrm{~kg} / \mathrm{m}^{2}$, while obesity was defined as a BMI of $\geq 30 \mathrm{~kg} / \mathrm{m}^{2}$. Long term use of immunosuppressive therapy (including corticosteroids and antineoplastic drugs) and acid suppressive therapy was defined as their use of one month or more during receiving ATT.

Laboratory investigations included microscopic examination of urine and stool by an experienced parasitologist, estimation of fasting serum level of glucose, liver chemistry panel, virology panel, kidney chemistry panel, and complete blood count. Diabetes mellitus (DM) was defined as serum level of glucose of $7 \mathrm{mmol} / \mathrm{L}$ or more. Liver chemistry panel included estimation of serum levels of alanine aminotransferase (ALT), aspartate aminotransferase (AST), alkaline phosphatase, bilirubin, and albumin. Virology panel included testing for serum antibody to hepatitis $\mathrm{C}$ virus (anti-HCV Ab), hepatitis $\mathrm{B}$ surface antigen (HBsAg), antibody to hepatitis B core (anti-HBc Ab), and antibody to human immunodeficiency virus (Anti-HIV Ab). Liver cirrhosis was diagnosed based on the compatible clinical, imaging, and laboratory criteria.

All the enrolled patients received the standard of care ATT therapy: INH ( $5 \mathrm{mg} / \mathrm{kg} /$ day; the maximum dose was $300 \mathrm{mg} /$ day), RIF (10 mg/ $\mathrm{kg}$ /day; the maximum dose was $600 \mathrm{mg} /$ day), PZA (30 mg/kg/day; the maximum dose was $2000 \mathrm{mg} /$ day $)$, and EMB (20 mg/kg/day; the maximum dose was $1600 \mathrm{mg} /$ day) for two months, followed by INH and RIF for extra four months [17]. They also received pyridoxine (vitamin B6, $50 \mathrm{mg} /$ day) during the entire treatment period for prophylaxis against isoniazid-related peripheral neuropathy [18].

For follow up, clinical evaluation and laboratory investigations were provided. Clinical evaluation on daily basis while admitted to the inpatient sectors, followed by clinical evaluation and laboratory investigations (liver chemistry panel) on weekly basis at the outpatient clinics for the first two months of therapy, and then monthly for rest of the period, were carried out. At the second month and the fourth month of therapy, sputum culture on Löwenstein-Jensen medium was performed for all the patients. Therapeutic failure of ATT was defined as positive sputum culture at the fourth month [4].

Immediate discontinuation of RIF and PZA for the patients who had elevated serum levels of ALT and/or AST (three times the upper limit of normal (ULN) or more with symptoms or five times the ULN with or without symptoms) during the first two months of ATT was carried out. Streptomycin (SM) was used with INH and EMB until resumption of RIF and PZA after decline of ALT and/or AST serum levels to less than two times the ULN. The dose of SM was $15 \mathrm{mg} / \mathrm{kg} /$ day by intramuscular injection, with a maximum daily dose of $1000 \mathrm{mg}$. For patients with the same criteria but after the first two months of ATT, RIF was replaced by EMB temporarily until it was resumed according to the previously mentioned rules [17].

\section{Statistical analysis}

Data were analyzed using the Statistical Package for Social Sciences (IBM SPSS Statistics, version 22.0, release 22.0.0.0; IBM Corp, Armonk, New York, US) for Microsoft Windows ${ }^{\oplus}$ (64-bit version). Results were expressed as mean \pm standard deviation or frequency (percentage) as appropriate. Student's t-test or Mann-Whitney U test, and Yates' corrected chi-squared test or Fischer's exact test as appropriate were used to compare the variables between the study groups. Multivariate analysis (binary logistic regression) was used to assess the independent effect of each predictor. Multivariate analysis included significant factors with $p<0.05$ in the univariate analyses.

The software $G^{\star}$ Power version 3.1.9.2 was used for a post hoc power analysis of the performed chi-square tests. An arbitrary effect size was chosen for the power analysis, which precisely was a Cohen's w statistic of 0.3 . This value conventionally corresponds to a medium sized effect. The power achieved was 0.84 .

\section{Ethical considerations}

The study was conducted after approval of the Clinical Research Ethical Committee of Assiut Faculty of Medicine and was carried out according to the code of ethics of the World Medical Association (Declaration of Helsinki). All the participants signed a consent certificate after discussing in detail with the investigators the certificate subjects and the study aim. Participants were clearly informed that refusing to participate in the study will not affect having full benefit of the available medical service. Data confidentiality was respected.

\section{Results}

After exclusion of 17 patients (3.4\%), the study included 483 naive patients with pulmonary TB. Among the patients excluded after the start of therapy, 11 were for inability to attend for follow up and six stopped treatment due to the adverse effects of the ATT (due to the hepatic adverse effects in four, vomiting in one, and pruritus in one). 
The demographic, clinical, imaging, and laboratory characteristics of the study population are shown in Table 1 . Their mean age was 37 \pm 12.5 years; $53.8 \%$ of them were males. Therapeutic response was achieved by $68.3 \%$ of the patients; $17 \%$ of the patients had adverse effects. Tobacco smoking was reported by $38.9 \%$ of the patients. Approximately, $31 \%$ of the patients had type- 2 DM; $17.8 \%$ were using metformin therapy either as a monotherapy or included in combination therapy. Helminth infection was detected among $19.1 \%$ of the patients (ascariasis among $12.3 \%$, ancylostomiasis among $8.5 \%$, and schistosomiasis among 1.7\%); infection with more than one helminth existed. Immunosuppressive therapy included corticosteroids and azathioprine, while acid suppressive therapy included omeprazole, famotidine, pantoprazole, esomeprazole, and ranitidine.

Table 2 shows the different types of adverse effects due to ATT among the study population with pulmonary TB. The most frequent one was elevated liver chemistry, which was detected among $9.7 \%$ of the patients. Among the study population with pulmonary TB, older age (equal to or more than 40 years old), tobacco smoking, long term immunosuppressive therapy, chronic obstructive pulmonary disease, DM, lack of metformin therapy, and helminth infection were significantly associated with therapeutic failure, as shown in Table 3. Table 4 shows the predictors of therapeutic failure among the study population with pulmonary TB. Diabetes mellitus, helminth infection, tobacco smoking, and lack of metformin therapy were significantly, independently associated with therapeutic failure Therapeutic outcome among the study population is shown in figure 1 .

Table 1. Demographic, clinical, imaging, and laboratory characteristics of the study population with pulmonary TB $(n=483)$.

\begin{tabular}{|l|l|}
\hline Age (years) & $37 \pm 12.5$ \\
\hline Age $\geq 40$ years & $91(18.8)$ \\
\hline Gender (male) & $260(53.8)$ \\
\hline Residence (rural) & $323(66.9)$ \\
\hline Tobacco smoking & $188(38.9)$ \\
\hline Alcohol consumption & $9(1.9)$ \\
\hline Therapeutic failure & $153(31.7)$ \\
\hline Adverse effects & $82(17)$ \\
\hline Long term immunosuppressive therapy & $85(17.6)$ \\
\hline Long term acid suppressive therapy * & $111(23)$ \\
\hline Fever & $352(72.9)$ \\
\hline Hemoptysis & $101(20.9)$ \\
\hline COPD & $134(27.7)$ \\
\hline CHF & $33(6.8)$ \\
\hline Obesity & $76(15.7)$ \\
\hline DM & $149(30.9)$ \\
\hline Metformin therapy & $86(17.8)$ \\
\hline Cavitary pulmonary lesions & $221(45.8)$ \\
\hline Pleural effusion & $15(3.1)$ \\
\hline Anemia & $130(26.9)$ \\
\hline Leukopenia & $32(6.6)$ \\
\hline Renal insufficiency & $43(8.9)$ \\
\hline Liver cirrhosis & $39(8.1)$ \\
\hline Helminth infection ** & $92(19.1)$ \\
\hline Anti-HCV Ab & $47(9.7)$ \\
\hline HBsAg & $23(4.8)$ \\
\hline Anti-HIV Ab & $1(0.2)$ \\
\hline $\begin{array}{l}\text { TB: tuberculosis; n: number; COPD: chronic obstructive pulmonary disease; CHF: } \\
\text { Congestive heart failure; DM: diabetes mellitus; Anti-HCV Ab: antibody to hepatitis } \\
\text { immunodeficiency virus. } \\
\text { Data are presented as frequency (percentage) }), \\
\text { 土 standard deviation. } \\
\text { * Immunosuppressive therapy included corticosteroid and antineoplastic therapy. } \\
* * \text { Helminth infection included ascariasis, ancylostomiasis, and schistosomiasis. }\end{array}$ \\
\hline
\end{tabular}

Table 2. Adverse effects among the study population with pulmonary TB $(n=483)$.

\begin{tabular}{|l|l|}
\hline Gastrointestinal & $43(8.9)$ \\
Epigastric pain & $29(6)$ \\
Nausea & $14(2.9)$ \\
Vomiting & $13(2.7)$ \\
Anorexia & \\
\hline Hepatic & $47(9.7)$ \\
\hline Elevated liver chemistry & $6(1.2)$ \\
\hline Jaundice & \\
\hline Dermatological & $25(5.2)$ \\
\hline Pruritus & $15(3.1)$ \\
\hline Musculoskeletal & \\
Myalgia & $41(8.5)$ \\
\hline Neurological & $27(5.6)$ \\
\hline Headache & \\
Insomnia & \\
\hline TB: tuberculosis; n: number. & \\
Data are presented as frequency (percentage). & \\
\hline
\end{tabular}

Data are presented as frequency (percentage).

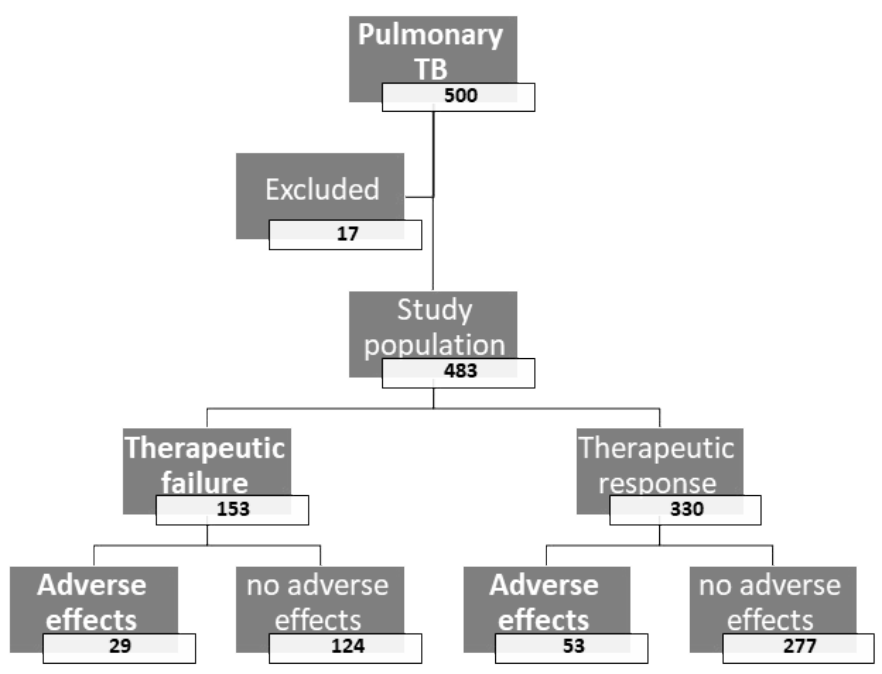

Figure 1. Flow chart of the therapeutic outcome among the study population with pulmonary tuberculosis. TB: tuberculosis.

\section{Discussion}

In Egypt, we are facing an increasing rate of therapeutic failure among patients with pulmonary TB. Our study results revealed that the therapeutic failure rate among naïve patients with pulmonary $\mathrm{TB}$ is $31.7 \%$. This rate is higher than the last reported rate among the Egyptian naïve patients with pulmonary TB (29.4\%) [19]. This higher rate may be attributed to the higher frequency of DM among our study patients (30.9\% vs $27.7 \%)$. A similar rate of therapeutic failure (30\%) was reported among the Korean patients with pulmonary TB, through a retrospective study [20]. In addition to Mtb resistance to ATT, comorbidities seem to play a pivotal role in increasing the rate of therapeutic failure.

One of such comorbidities, DM, was a predictor of therapeutic failure among our study population. Several studies reported such an association with OR ranging between 2.5 and 6.7 [19,21-23]. Diabetics have lower levels of interferon-gamma and interleukin-22, which are essential for TB defense [24,25]. Also, high insulin level is associated with decreased type-1 T-helper cells immunity through a reduction in the type- 1 to type-2 T-helper cell ratio and interferon-gamma to interleukin-4 ratio [26]. In addition to the defect in cytokine secretion, there is a reduction in the capacity of the peripheral blood monocytes to bind and engulf $\mathrm{Mtb}$ among the patients with type-2 DM due to altered 
Table 3. Factors associated with therapeutic failure among the study population with pulmonary TB $(\mathrm{n}=483)$

\begin{tabular}{|c|c|c|c|}
\hline & Therapeutic failure $(n=153)$ & Therapeutic response $(n=330)$ & $p$ \\
\hline Age $\geq 40$ years & $41(26.8)$ & $50(15.2)$ & $0.029 * * * *$ \\
\hline Gender (male) & $79(51.6)$ & $181(54.9)$ & 0.528 \\
\hline Residence (rural) & $117(76.5)$ & $206(62.4)$ & 0.211 \\
\hline Tobacco smoking & $73(47.7)$ & $115(34.9)$ & $0.046 * * * *$ \\
\hline Alcohol consumption & $4(2.6)$ & $5(1.5)$ & 0.097 \\
\hline Long term immunosuppressive therapy * & $37(24.2)$ & $48(14.6)$ & $0.040 * * * *$ \\
\hline Long term acid suppressive therapy $* *$ & $40(26.1)$ & $71(21.5)$ & 0.362 \\
\hline Fever & $98(64.1)$ & $254(77)$ & 0.103 \\
\hline Hemoptysis & $38(24.8)$ & $63(19.1)$ & 0.252 \\
\hline COPD & $58(37.9)$ & $76(23)$ & $0.038 * * * *$ \\
\hline $\mathrm{CHF}$ & $12(7.8)$ & $21(6.4)$ & 0.501 \\
\hline Obesity & $25(16.3)$ & $51(15.5)$ & 0.627 \\
\hline $\mathrm{DM}$ & $66(43.1)$ & $83(25.2)$ & $0.002 * * * *$ \\
\hline Metformin therapy & $18(11.8)$ & $68(20.6)$ & $0.015 * * * *$ \\
\hline Cavitary pulmonary lesions & $87(56.9)$ & $134(40.6)$ & 0.066 \\
\hline Pleural effusion & $6(3.9)$ & $9(2.7)$ & 0.118 \\
\hline Anemia & $45(29.4)$ & $85(25.8)$ & 0.359 \\
\hline Leukopenia & $13(8.5)$ & $19(5.8)$ & 0.102 \\
\hline Renal insufficiency & $15(9.8)$ & $28(8.5)$ & 0.494 \\
\hline Liver cirrhosis & $16(10.5)$ & $23(7)$ & 0.087 \\
\hline Helminth infection $* * *$ & $43(28.1)$ & $49(14.9)$ & $0.001 * * * *$ \\
\hline Anti-HCV Ab & $12(7.8)$ & $35(10.6)$ & 0.109 \\
\hline HBsAg & $7(4.6)$ & $16(4.9)$ & 0.613 \\
\hline Anti-HIV Ab & $1(0.07)$ & 0 & na \\
\hline Adverse effects & $29(19)$ & $53(16.1)$ & 0.218 \\
\hline \multicolumn{4}{|c|}{$\begin{array}{l}\text { TB: tuberculosis; n: number; COPD: chronic obstructive pulmonary disease; CHF: congestive heart failure; DM: diabetes mellitus; Anti-HCV Ab: antibody to hepatitis C virus; HBsAg } \\
\text { Hepatitis B surface antigen; Anti-HIV Ab: antibody to human immunodeficiency virus; na: not applicable. } \\
\text { Data are presented as frequency (percentage), except for age which is presented as mean } \pm \text { standard deviation. } \\
\text { * Immunosuppressive therapy included corticosteroid and antineoplastic therapy. } \\
\text { ** Helminth infection included ascariasis, ancylostomiasis, and schistosomiasis. } \\
\text { *** Statistically significant. }\end{array}$} \\
\hline
\end{tabular}

Table 4. Predictors of therapeutic failure among the study population with pulmonary TB $(\mathrm{n}=483)$.

\begin{tabular}{|c|c|c|c|}
\hline & OR & $95 \% \mathrm{CI}$ & $p$ \\
\hline DM & 5.6 & $2.1-24.8$ & $0.007 * *$ \\
\hline Helminth infection * & 4.3 & $1.8-32.5$ & $0.011 * *$ \\
\hline Tobacco smoking & 2.5 & $1.2-41.7$ & $0.009 * *$ \\
\hline Metformin therapy & 0.7 & $0.3-1.2$ & $0.024 * *$ \\
\hline \multicolumn{4}{|c|}{$\begin{array}{l}\text { TB: tuberculosis; n: number; OR: odds ratio; CI: confidence interval; DM: diabetes } \\
\text { mellitus. } \\
\text { * Helminth infection included ascariasis, ancylostomiasis, and schistosomiasis. } \\
\text { ** Statistically significant. }\end{array}$} \\
\hline
\end{tabular}

complement pathway of opsonization [27]. Oral hypoglycemic drugsrifampin interaction leading to decreased absorption of rifampin may contribute to the therapeutic failure among the diabetic patients with pulmonary TB [28]. In the patients with DM, neutrophils have reduced chemotaxis and oxidative killing potential, and bactericidal activity $[29,30]$.

While DM was a predictor of therapeutic failure among our study patients with pulmonary $\mathrm{TB}$, the use of metformin therapy was found to be protective against therapeutic failure of ATT. It was reported that metformin use is protective against TB infection among patients with DM, irrespective of the dose [31]. Metformin has anti-inflammatory properties through the activation of adenosine monophosphate kinase, which promotes a switch from glycolysis to oxidative phosphorylation in response to low intracellular adenosine triphosphate [32]. This results in reduction of inflammatory cells proliferation burning glucose for energy (glycolysis), while promoting the noninflammatory cells burning fatty acids instead (fatty acid oxidation). Subsequently, inflammation is reduced through enhancing the formation of antiinflammatory M2 macrophages, and T-regulatory and CD8 memory T cells $[33,34]$. In addition, metformin promotes mitochondrial reactive oxygen species required for destruction of Mtb killing in Mtb-infected macrophages [35].

Co-infection with helminths can negatively affect the therapeutic response to ATT as shown by the results of our study. It was reported that ancylostomiasis resulted in significantly higher therapeutic failure rate among naïve patients with pulmonary TB [19]. Helminth infection reduces the immune response to the intracellular pathogens such as Mtb [36]; they enhance the cytokine response by type-2 T-helper cells, while they suppress type-1 T-helper cell response protecting against intracellular pathogens [37].

We found that tobacco smoking is another predictor of therapeutic failure among our study patients with pulmonary TB. Tobacco smoking is associated with a higher risk of infection with Mtb, development of active TB, TB-related mortality, poor therapeutic outcome, and recurrence of TB $[38,39]$.

Our study lacks antimicrobial sensitivity testing. We did not have data about the precise dose of metformin and the daily number of cigarettes used, which is considered as another limitation of this study. However, this study included a large number of patients and is considered the first of its type among the Egyptian, naive, patients with pulmonary $\mathrm{TB}$. 


\section{Conclusions}

In conclusion, the therapeutic failure rate of ATT among the Egyptian, naïve patients with pulmonary $\mathrm{TB}$ is increasing. The predictors of therapeutic failure include DM, lack of metformin use, helminth infection, and tobacco smoking. Further studies to explore the potential mechanisms explaining the role of metformin in enhancing the therapeutic response of ATT are recommended.

\section{References}

1. World Health Organization. Global tuberculosis report 2016. Available at: http:// wwwwhoint/tb/publications/global_report/gtbr2016_main_textpdf?ua $=1$

2. Combs DL, O'Brien RJ, Geiter LJ (1990) USPHS Tuberculosis Short-Course Chemotherapy Trial 21: effectiveness, toxicity, and acceptability. The report of final results. Ann Intern Med 112: 397-406. [Crossref]

3. Blumberg HM, Burman WJ, Chaisson RE, Daley CL, Etkind SC, et al. (2003) American Thoracic Society/Centers for Disease Control and Prevention/Infectious Diseases Society of America: treatment of tuberculosis. Am J Respir Crit Care Med 167: 603-662. [Crossref]

4. World Health Organization Definitions and Reporting Framework for Tuberculosis, 2013. Revision: WHO/HTM/TB/2013.2. World Health Organization, Geneva (2013). Available at: http://apps.who.int/iris/bitstream/10665/79199/1/9789241505345_eng. pdf

5. Ellner JJ (2016) Goldman L, Schafer AI (eds), Goldman-Cecil Medicine, ElsevierSaunders, Philadelphia: 2030-2039

6. International Diabetese Fedration. International Diabetese Fedration Atals 2015. Available at: http://www.diabetesatlas.org/

7. Jeon CY, Murray MB (2008) Diabetes mellitus increases the risk of active tuberculosis: a systematic review of 13 observational studies. PLoS Med 5: e152. [Crossref]

8. Leung CC, Lam TH, Chan WM, Yew WW, Ho KS, et al. (2008) Diabetic control and risk of tuberculosis: a cohort study. Am J Epidemiol 167: 1486-1494. [Crossref]

9. Al-Rifai RH, Pearson F, Critchley JA, Abu-Raddad LJ (2017) Association between diabetes mellitus and active tuberculosis: A systematic review and meta-analysis. PLoS One 12: e187967. [Crossref]

10. Baker MA, Harries AD, Jeon CY, Hart JE, Kapur A, et al. (2011) The impact of diabetes on tuberculosis treatment outcomes: a systematic review. BMC Med 9: 81. [Crossref]

11. Kumar NP, Sridhar R, Banurekha VV, Jawahar MS, Nutman TB, et al. (2013) Expansion of pathogen-specific T-helper 1 and T-helper 17 cells in pulmonary tuberculosis with coincident type 2 diabetes mellitus. J Infect Dis 208: 739-748. [Crossref]

12. Faurholt-Jepsen D, Range N, PrayGod G, Jeremiah K, Faurholt-Jepsen M, et al. (2013) Diabetes is a strong predictor of mortality during tuberculosis treatment: a prospective cohort study among tuberculosis patients from Mwanza, Tanzania. Trop Med Int Health 18: 822-829. [Crossref]

13. Giacco F, Brownlee M (2010) Oxidative stress and diabetic complications. Circ Res 107: 1058-1070. [Crossref]

14. Palanisamy GS, Kirk NM, Ackart DF, Shanley CA, Orme IM, et al. (2011) Evidence for oxidative stress and defective antioxidant response in guinea pigs with tuberculosis. PLoS One 6: e26254. [Crossref]

15. Vashisht R, Brahmachari SK (2015) Metformin as a potential combination therapy with existing front-line antibiotics for Tuberculosis. J Transl Med 13: 83. [Crossref]

16. Restrepo BI (2016) Metformin: Candidate host-directed therapy for tuberculosis in diabetes and non-diabetes patients. Tuberculosis (Edinb) 101S: S69-69S72. [Crossref]

17. World Health Organization, Treatment of Tuberculosis: Guidelines for National Programs, WHO/HTM/TB/2009.420, fourth ed., World Health Organization, Geneva, 2009.

18. van der Watt JJ, Harrison TB, Benatar M, Heckmann JM (2011) Polyneuropathy, antituberculosis treatment and the role of pyridoxine in the HIV/AIDS era: a systematic review. Int J Tuberc Lung Dis 15: 722-728. [Crossref]

19. Hasanain AF, Zayed AA, Mahdy RE, Nafee AM, Attia RA, et al. (2015) Hookworm infection among patients with pulmonary tuberculosis: Impact of co-infection on the therapeutic failure of pulmonary tuberculosis. Int J Mycobacteriol 4: 318-322. [Crossref]
20. Park YS1, Hong SJ, Boo YK, Hwang ES, Kim HJ, et al. (2012) The national status of tuberculosis using nationwide medical records survey of patients with tuberculosis in Korea. Tuberc Respir Dis (Seoul) 73: 48-55. [Crossref]

21. Choi H, Lee M, Chen RY, Kim Y, Yoon S, et al. (2014) Predictors of pulmonary tuberculosis treatment outcomes in South Korea: a prospective cohort study, 20052012. BMC Infect Dis 14: 360. [Crossref]

22. Hongguang C, Min L, Shiwen J, Fanghui G, Shaoping H, et al. (2015) Impact of diabetes on clinical presentation and treatment outcome of pulmonary tuberculosis in Beijing. Epidemiol Infect 143: 150-156. [Crossref]

23. Mi F, Tan S, Liang L, Harries AD, Hinderaker SG, et al. (2013) Diabetes mellitus and tuberculosis: pattern of tuberculosis, two-month smear conversion and treatment outcomes in Guangzhou, China. Trop Med Int Health 18: 1379-1385. [Crossref]

24. Martens GW1, Arikan MC, Lee J, Ren F, Greiner D, et al. (2007) Tuberculosis susceptibility of diabetic mice. Am J Respir Cell Mol Biol 37: 518-524. [Crossref]

25. Aujla SJ, Chan YR, Zheng M, Fei M, Askew DJ, et al. (2008) IL-22 mediates mucosa host defense against Gram-negative bacterial pneumonia. Nat Med 14: 275-281. [Crossref]

26. Viardot A, Grey ST, Mackay F, Chisholm D (2007) Potential antiinflammatory role of insulin via the preferential polarization of effector $\mathrm{T}$ cells toward a $\mathrm{T}$ helper 2 phenotype. Endocrinology 148: 346-353. [Crossref]

27. Gomez DI, Twahirwa M, Schlesinger LS, Restrepo BI (2013) Reduced Mycobacterium tuberculosis association with monocytes from diabetes patients that have poor glucose control. Tuberculosis (Edinb) 93: 192-197. [Crossref]

28. Nijland HM, Ruslami R, Stalenhoef JE, Nelwan EJ, Alisjahbana B, et al. (2006) Exposure to rifampicin is strongly reduced in patients with tuberculosis and type 2 diabetes. Clin Infect Dis 43: 848-854. [Crossref]

29. Delamaire M, Maugendre D, Moreno M, Le Goff MC, Allannic H, et al. (1997) Impaired leucocyte functions in diabetic patients. Diabet Med 14: 29-34. [Crossref]

30. Rayfield EJ, Ault MJ, Keusch GT, Brothers MJ, Nechemias C, et al. (1982) Infection and diabetes: the case for glucose control. Am J Med 72: 439-450. [Crossref]

31. Marupuru S, Senapati P1, Pathadka S1, Miraj SS2, Unnikrishnan MK1, et al. (2017) Protective effect of metformin against tuberculosis infections in diabetic patients: an observational study of south Indian tertiary healthcare facility. Braz J Infect Dis 21: 312-316. [Crossref]

32. Zhou G, Myers R, Li Y, Chen Y, Shen X, et al. (2001) Role of AMP-activated protein kinase in mechanism of metformin action. J Clin Invest 108: 1167-1174. [Crossref]

33. Yin Y, Choi SC, Xu Z, Perry DJ, Seay H, et al. (2015) Normalization of CD4+ T cell metabolism reverses lupus. Sci Transl Med 7: 274ra18. [Crossref]

34. Huang SC, Everts B, Ivanova Y, O'Sullivan D, Nascimento M, et al. (2014) Cellintrinsic lysosomal lipolysis is essential for alternative activation of macrophages. Nat Immunol 15: 846-855. [Crossref]

35. Singhal A, Jie L, Kumar P, Hong GS, Leow MK, et al. (2014) Metformin as adjunct antituberculosis therapy. Sci Transl Med 6: 263ra159. [Crossref]

36. Bentwich Z, Kalinkovich A, Weisman Z (1995) Immune activation is a dominant factor in the pathogenesis of African AIDS. Immunol Today 16: 187-191. [Crossref]

37. Brooker S, Bethony J, Hotez PJ (2004) Human hookworm infection in the 21 st century. Adv Parasitol 58: 197-288. [Crossref]

38. Zellweger JP, Cattamanchi A, Sotgiu G (2015) Tobacco and tuberculosis: could we improve tuberculosis outcomes by helping patients to stop smoking? Eur Respir J 45: 583-585. [Crossref]

39. Wampande EM, Mupere E, Debanne SM, Asiimwe BB, Nsereko M, et al. (2013) Longterm dominance of Mycobacterium tuberculosis Uganda family in peri-urban KampalaUganda is not associated with cavitary disease. BMC Infect Dis 13: 484. [Crossref]

Copyright: (C)2018 Hasanain AFA. This is an open-access article distributed under the terms of the Creative Commons Attribution License, which permits unrestricted use, distribution, and reproduction in any medium, provided the original author and source are credited. 